American Journal of Environmental Sciences 5 (1): 53-57, 2009

ISSN 1553-345X

(C) 2009 Science Publications

\title{
Diffusion of Radioactive Materials in the Atmosphere
}

\author{
${ }^{1}$ Abdul-Wali Ajlouni, ${ }^{1}$ Manal Abdelsalam, ${ }^{1}$ Hussam Al-Rabai' ah and ${ }^{2}$ Abdullah M.S. Ajlouni \\ ${ }^{1}$ Department of Applied Physics, Tafila Technical University, Tafila, Jordan \\ ${ }^{2}$ Department of Science, Husun Technical College, Amman, Jordan
}

\begin{abstract}
Problem statement: The dispersion of radioactive materials in the environment related to escaping of noble gases, halogens and aerosols of non-volatile radioactive materials, from the reactor containment during normal operations, or in the event of a sever reactor accident. Approach: radionuclide dispersion in the environment is demonstrated by mathematical tools which are the partial differential equations, mainly the diffusion equation. A mathematical model to calculate the concentration of nuclear pollutants (radioactivity) with certain boundary conditions is constructed. Results: Solving the mathematical model and using some approximations lead to a distribution represents a model for plume of radioactive pollutants dispersed in two dimensions normal to the wind direction in which the plume moves as an entire non-dispersible unit. Conclusion: The obtained result theoretically are very close to those achieved experimentally.
\end{abstract}

Key words: Radioactive materials, diffusion equation, mathematical modeling, Jordan atmosphere

\section{INTRODUCTION}

The artificial creation of radionuclides may result from physical processes involving nuclear fission, nuclear fusion and neutron activation. The most important source of artificially created radionuclides is neutron-induced nuclear fission. The chemical and physical forms of the active species determine deposition, migration and uptake are radioactivity by living organisms.

A variety of systems and processes may introduce radioactivity into the environment. Human activities involving nuclear weapons and the nuclear fuel cycle (including mining, milling, fuel enrichment and fabrication, reactor operation, spent fuel storage and reprocessing and waste storage), leading to significant creation and release of radioactivity. Human technology also releases pre-existing natural radionuclides, which would otherwise remain trapped in the earth's crust ${ }^{[1]}$.

The physical and chemical form of radionuclides may vary depending on the release and transport conditions in addition to the element properties. A general distinction can be made between gases, aerosols and particulate material. The most serious dispersion of radioactive materials in the environment is that related to escaping of noble gases, halogens and aerosols of non-volatile radioactive materials, from the reactor containment in the event of a sever reactor accident ${ }^{[1]}$. In this study we try to make a mathematical simulation of radionuclide dispersion in the environment by matching the mathematical tools which are the partial differential equations, mainly the diffusion equation and the technical data of the nuclear reactors. This simulation may help in determination of radiation dose may received by the public during a sever reactor accident. A demonstration, with a computer program, reflecting the Jordanian atmosphere, will be carried out; the results from this demonstration will be compared with real data taken from the field. The study is arranged as follows. First, we introduce the main concepts of the Partial Differential Equations (PDEs) and their applications. Then, we introduce the main features of transport phenomena with emphasis on the diffusion equation and its application in dispersion of radioactive materials as atmospheric pollution. Finally, arithmetic calculations related to Jordan atmosphere is carried out.

\section{MATERIALS AND METHODS}

Partial differential equations: A PDE is an equation that contains partial derivatives, in which the unknown function depends on several variables, e.g., temperature depends both on location $\mathrm{x}$ and time $\mathrm{t}$. The variables $\mathrm{x}$ and $t$ are called independent variables, whereas the unknown variable which we differentiate, e.g., temperature, is called dependent variable ${ }^{[2-4]}$.

Most physical phenomena, whether in the domain of fluid dynamics, electricity, magnetism, mechanics, optics, or heat flow, can be described in general by 
Partial Differential Equations (PDEs). Simplifications can be made to reduce the equations in question to ordinary differential equations, but, nevertheless, the complete description of the systems resides in the general area of PDEs. Most of the natural laws of physics, such as Maxwell's equations, Newton's laws of motion and Schrödinger equation, are stated, or can be, in terms of PDEs, that is, these laws describe physical phenomena by relating space and time derivatives. Derivatives occur in these equations because the derivatives represent natural things, like velocity, acceleration, force, friction and current. Hence, we have equations relating partial derivatives of some unknown quantity that we would like to find ${ }^{[2-4]}$.

The most important PDEs in physical sciences are Equation of continuity: For a fluid of density $\rho(\vec{r}, t)$, which has an element velocity $\vec{v}(\vec{r}, t)$ at the position $\vec{r}$ at the time t. The rate of increase of mass per unit volume equals the net rate of mass addition per unit volume by convection, or:

$$
\frac{\partial \rho}{\partial t}+\vec{\nabla} \cdot(\rho \vec{v})=0
$$

Equation of diffusion or heat flow: The basic process in the diffusion phenomenon is the flow of the fluid from a region of higher density to one of lower density. The flow vector $\vec{J}=\rho \vec{v}$ can be represented as:

$$
\vec{J}=-a^{2} \vec{\nabla} \rho
$$

where, $a^{2}$ is the diffusion constant of the medium. With the use of Eq. 1 and 2, we get the equation of diffusion:

$$
\frac{\partial \rho}{\partial \mathrm{t}}-\mathrm{a}^{2} \nabla^{2} \rho=0
$$

Denoting the temperature function by $\mathrm{u}(\overrightarrow{\mathrm{r}}, \mathrm{t})$, the flow of heat from regions of higher temperature to those of lower temperature may be described by the equation of heat flow:

$$
\frac{\partial \mathrm{u}}{\partial \mathrm{t}}-\mathrm{a}^{2} \nabla^{2} \mathrm{u}=0
$$

where, $\mathrm{a}=\mathrm{K} / \sigma \rho$, with $\mathrm{K}, \sigma$ and $\mathrm{p}$ are the thermal conductivity, the specific heat and density of the material, through which the heat flows, respectively.

Schrödinger equation for a free particle: With a simple division, the Schrödinger equation for a single particle of mass $m$ in the absence of any applied force field can be rewritten in the following way: $\frac{\partial \Psi}{\partial \mathrm{t}}-\frac{\mathrm{i} \hbar}{2 \mathrm{~m}} \nabla^{2} \Psi=0$

Where:

$\mathrm{I}=$ The unit imaginary number,

$\hbar=$ Planck's constant divided by $2 \pi$ and

$\Psi=$ The wave function of the particle

This equation is a mathematical analogue of the particle diffusion equation, which one obtains through easy transformation ${ }^{[2-4]}$.

In addition to the above mentioned equations, there are many equations like the vibrating string equation, Laplacee's equation, longitudinal vibrations of a beam, transverse vibrations of a beam and many other PDEs that represent physical phenomena.

To solve a PDE there are many methods, the most important of them are those that change PDEs into Ordinary Differential Equations (ODE). The method of separation of variables which reduces a PDE in $n$ variables to $\mathrm{n}$ ODEs, almost is the first and famous technique to solve a PDE. Other methods are integral transforms, change of coordinates, transformation of dependent variables, numerical methods, perturbation methods, integral equations, calculus of variations methods and eigenfunction expansion ${ }^{[2-4]}$.

All physical problems have boundaries of some kind, called boundary conditions, so we must describe mathematically what goes on there in order to adequate the problem. These problems must start from some value of time, generally assumed $t=0$, so we must specify the physical apparatus at this time. By writing the PDE which represents the physical problem and the equations of boundary and initial conditions, we have what is called an Initial-Boundary-Value Problem (IBVP).

Transport phenomena: The subject of transport phenomena includes three closely related topics: fluid dynamics, heat transfer and mass transfer. Fluid dynamics involves the transport of momentum, heat transfer deals with the transport of energy and mass transfer is concerned with the transport of mass of various chemical species. These three transport phenomena should be studied together for the following reasons:

- They frequently occur simultaneously in industrial, biological, agricultural and meteorological problems

- The basic equations that describe the three transport phenomena are closely related. This 
similarity of the equations under simple conditions is the basis for solving problems "by analogy"

- The mathematical tools needed for describing these phenomena are very similar

- The molecular mechanisms underlying the various transport phenomena are very closely related. All materials are made up of molecules and the same molecular motion and interactions are responsible for viscosity, thermal conductivity and diffusion

The description of our physical problem requires three types of equations:

- The PDE describing the physical phenomenon of diffusion

- The boundary conditions describing the physical nature of our problems on the boundaries

- The initial conditions describing the physical phenomenon at the start of the experiment ${ }^{[5]}$

Diffusion equation: the basic equation of onedimensional diffusion is the relationship:

$$
\frac{\partial \rho}{\partial t}-a^{2} \frac{\partial^{2} \rho}{\partial x^{2}}=0
$$

Which relates the quantities:

$\frac{\partial \rho}{\partial t}=$ The rate of change in density with respect to time measured in particle per unit of volume per second

$\frac{\partial^{2} \rho}{\partial x^{2}}=$ The concavity of the density profile $p(x, t)$, which essentially compares the density at one point to the density at neighboring points. Eq. 6 is extended to Eq. 3 in three dimensions ${ }^{[2-5]}$

When nuclear pollutants released from the nuclear reactor to the atmosphere, atmospheric eddy currents causes a turbulent diffusion, which makes a pure mathematical description of the phenomenon is not completely expressed by the diffusion equation. Hence, approximations should be made and predictions of some semi-empirical models like the Gaussian plume model. Or, to treat the problem as an ideal situation and then try to introduce other parameters that affect the results as what we are going to do here. The atmospheric concentration of a nuclide is expressed by the diffusion equation:

$$
\frac{\partial N}{\partial t}=K_{x} \frac{\partial^{2} N}{\partial x^{2}}+K_{y} \frac{\partial^{2} N}{\partial y^{2}}+K_{z} \frac{\partial^{2} N}{\partial z^{2}}
$$

Where:

$\mathrm{N}(\mathrm{x}, \mathrm{y}, \mathrm{z}, \mathrm{t})=$ The concentration of the nuclide in Becquerel per cubic meter

$\mathrm{K}_{\mathrm{x}}, \mathrm{K}_{\mathrm{y}}$ and $\mathrm{K}_{\mathrm{z}}=$ The diffusion coefficients in the $\mathrm{x}, \mathrm{y}$ and $\mathrm{z}$ directions, respectively

The initial conditions could be written as:

$\mathrm{N}(\mathrm{x}, \mathrm{y}, \mathrm{z}, \mathrm{t}=\mathrm{o})=\mathrm{Q} \delta(\mathrm{x}) \delta(\mathrm{y}) \delta(\mathrm{z})$

where, we have assumed that the instantaneous release of $\mathrm{Q}$ Becquerel $(\mathrm{Bq})$ occurs at $\mathrm{x}=\mathrm{y}=\mathrm{z}=\mathrm{t}=0$ and $\delta(\bar{x}), \delta(\bar{y})$ and $\delta(\bar{z})$ are the Dirac delta functions. The boundary conditions are $\mathrm{N}(\mathrm{x}, \mathrm{y}, \mathrm{z}, \mathrm{t})=\mathrm{o}$ and:

$\frac{\partial \mathrm{N}}{\partial \mathrm{x}}=\frac{\partial \mathrm{N}}{\partial \mathrm{y}}=\frac{\partial \mathrm{N}}{\partial \mathrm{z}}=\mathrm{o}$ as $\mathrm{x}, \mathrm{y}, \mathrm{z} \rightarrow \infty$

Using the method of separation of variables, Eq. 7 will have the three dimensional spatial solutions as:

$N(x)=\frac{1}{\sqrt{2 \pi} \sigma_{x}} \cdot e^{-\frac{x^{2}}{2 \sigma^{2}}}$

$\mathrm{N}(\mathrm{y})=\frac{1}{\sqrt{2 \pi} \sigma_{\mathrm{y}}} \mathrm{e}^{-\frac{\mathrm{y}^{2}}{2 \sigma^{2}}}$

and

$\mathrm{N}(\mathrm{z})=\frac{1}{\sqrt{2 \pi} \sigma_{\mathrm{z}}} \mathrm{e}^{-\frac{\mathrm{z}^{2}}{2 \sigma^{2}}}$

It is easy to find that, the standard deviation which represents the dispersion coefficient is:

$\sigma=\sqrt{2 \mathrm{Kt}}$

This leads to the general solution:

$\mathrm{N}(\mathrm{x}, \mathrm{y}, \mathrm{z}, \mathrm{t})=\mathrm{Q} \frac{\mathrm{e}^{-\frac{\mathrm{x}^{2}}{4 \mathrm{k}_{\mathrm{x}} \mathrm{t}}}}{\sqrt{4 \pi \mathrm{k}_{\mathrm{x}} \mathrm{t}}} \frac{\mathrm{e}^{-\frac{\mathrm{y}^{2}}{4 \mathrm{k}_{\mathrm{y}} \mathrm{t}}}}{\sqrt{4 \pi \mathrm{k}_{\mathrm{y}} \mathrm{t}}} \cdot \frac{\mathrm{e}^{-\frac{\mathrm{z}^{2}}{4 \mathrm{k}_{\mathrm{z}} \mathrm{t}}}}{\sqrt{4 \pi \mathrm{k}_{\mathrm{z}} \mathrm{t}}}$

This solution could be modified for insertion of wind speed, $u$ and the height of the release point from 
the ground surface h, which changes the main spatial variables as follows:

$$
\left.\begin{array}{l}
\mathrm{x}=\mathrm{x}+\mathrm{ut} \\
\mathrm{z}=\mathrm{z}+\mathrm{h} \\
\mathrm{y}=\mathrm{y}
\end{array}\right\}
$$

Substitution of these new variables in Eq. 14 yields:

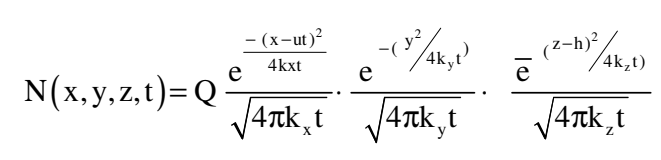

\section{RESULTS}

By assuming the speed wind is highly effective than self-diffusion. Eq. 16 is reduced to:

$$
\mathrm{N}(\mathrm{x}, \mathrm{y}, \mathrm{z}, \mathrm{t})=\frac{\mathrm{Q}}{2 \pi \mathrm{u} \sigma_{\mathrm{y}} \sigma_{\mathrm{z}}} \mathrm{e}^{\left(\frac{-\mathrm{y}^{2}}{2 \sigma_{\mathrm{y}}^{2}}-\frac{\left(\mathrm{z}-\mathrm{h}^{2}\right)}{\mathrm{z \sigma _{z } ^ { 2 }}}\right)} \cdot \delta\left(\frac{\mathrm{x}}{\mathrm{v}}-\mathrm{t}\right)
$$

which describes a plume of polluting radionuclide moving in the $\mathrm{x}$ direction as an entire unit, while spreading by diffusion in the two other directions.

If the source is continuously releases pollutant radionuclide, $Q^{\prime}(\mathrm{t})$, the concentration on the surface of Earth, $\mathrm{z}=0$, is given by:

$$
\mathrm{N}(\mathrm{x}, \mathrm{y}, \mathrm{t})=\frac{\mathrm{Q}^{\prime}(\mathrm{t})}{\pi \mathrm{u} \sigma_{\mathrm{y}} \sigma_{\mathrm{z}}} \mathrm{e}^{-\left(\frac{\mathrm{y}^{2}}{2 \sigma_{\mathrm{y}}^{2}}+\frac{\mathrm{h}^{2}}{2 \sigma_{\mathrm{z}}^{2}}\right)} \cdot \delta\left(\frac{\mathrm{x}}{\mathrm{v}}-\mathrm{t}\right)
$$

with an accumulative, time-independent, pollution concentration:

$$
\mathrm{N}(\mathrm{x}, \mathrm{y})=\frac{\mathrm{Q}}{\pi \mathrm{u} \sigma_{\mathrm{y}} \sigma_{\mathrm{z}}} \mathrm{e}^{-\left(\frac{\mathrm{y}^{2}}{2 \sigma_{\mathrm{y}}^{2}}+\frac{\mathrm{h}^{2}}{2 \sigma_{z}^{2}}\right)}
$$

By differentiating Eq. 19, the maximum surface concentration could be obtained if the release point height is:

$$
\mathrm{h}=\sqrt{2} \sigma_{\mathrm{z}}
$$

In reference to Eq. 19, it is noticed that the surface pollutant concentration depends inversely on $\sigma_{\mathrm{y}}$ and $\sigma_{\mathrm{x}}$. So, in order to get surface pollutant concentration at any point $(\mathrm{x}, \mathrm{y})$, we should get $\sigma_{\mathrm{y}}$ and $\sigma_{\mathrm{x}}$ using the Fig. 1. In Fig. 1, there are six types of weather conditions ${ }^{[6]}$ :
A. Extremely unstable conditions

B. Moderately unstable conditions

C. Slightly unstable conditions

D. Neutral conditions

E. Slightly stable conditions

F. Moderately stable conditions
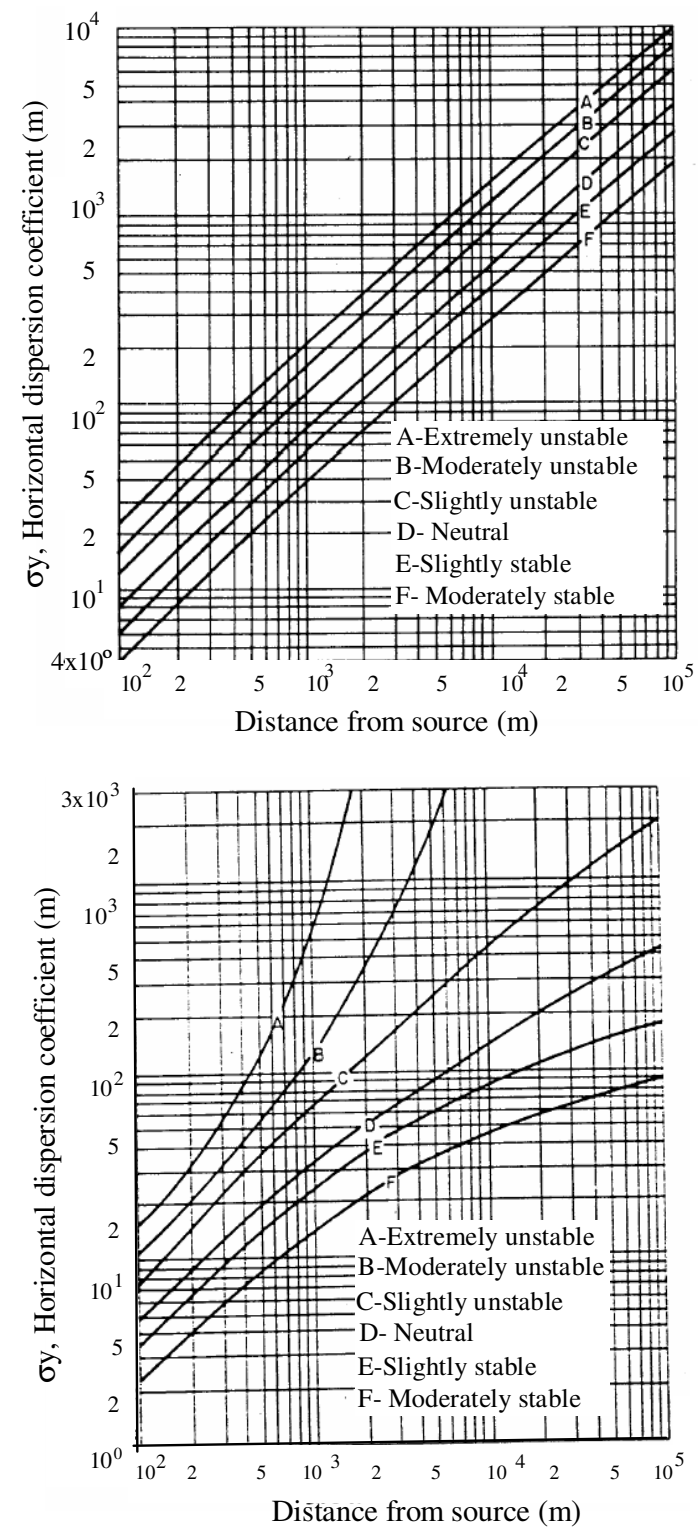

Fig. 1: Horizontal dispersion coefficient $\sigma_{\mathrm{y}}$ (left) and vertical dispersion coefficient $\sigma_{\mathrm{x}}$ (right), versus downwind distance from source for different turbulence categories ${ }^{[6]}$

In the last 30 years, the average wind speed in Jordan was about $2 \mathrm{~m} \mathrm{~s}^{-2}$, hence the best situation to 
describe Jordan weather conditions is C-Slightly unstable conditions.

\section{DISCUSSION}

In Jordan, there are no nuclear reactors, but, if any nuclear pollution occurs, it must come out of boarders, where the nearest nuclear reactor is Dimona $26 \mathrm{MW}$ rector located in the southern part of Israel. By choosing $\mathrm{Cs}^{137}$ nuclide which has a long half life, about 30 years, so the calculations will not be affected by the radioactive decay of this radionuclide. Part of $\mathrm{Cs}^{137}$ produced inside the reactor will be ordinarily released at a rate of $3.15 \times 10^{6}$ Becquerel's (Bq) per MW per Year, thus for a period of 5 years, $4.1 \times 10^{8} \mathrm{~Bq}$ are assumed to be released from the $26 \mathrm{MW}$ reactor. Using the aforementioned numbers in application of Eq. 19 in calculating surface concentration of $\mathrm{Cs}^{137}$ nuclide at a point located at $25 \mathrm{~km}$ east of the reactor, with $2 \mathrm{~km}$ width, $\mathrm{y}=1$, leads to:

$$
\mathrm{N}(\mathrm{x}, \mathrm{y})=36 \mathrm{~Bq} / \mathrm{m}^{2}
$$

If the width is to be more than $2 \mathrm{~km}, \mathrm{y}>1$, the surface concentration is:

$$
\mathrm{N}(\mathrm{x}, \mathrm{y})=2 \mathrm{~Bq} / \mathrm{m}^{2}
$$

To give a general application o Eq. 19, a computer $\mathrm{C}++$ program is introduced below. Results are represented in Table 1. Results in the Table 1 showed that the surface concentration is increasing as we go from $500 \mathrm{~m}-4000 \mathrm{~m}$ and then start increasing. The maximum surface concentration is transformed from the distance $\mathrm{h} / \sqrt{2}$, as represented in Eq. 21, to $4000 \mathrm{~m}$ due to effects of wind speed. This will make the pollutant distribution go far from the normal distribution. Also, the increase pattern of concentration on the left side of the line, that represent the maximum, is faster than the decrease pattern on the right side of the line, i.e., the distribution curve is not symmetric about the line $4000 \mathrm{~m}$.

Table 1: General application: Result of $\mathrm{C}++$ program

\begin{tabular}{lcccc}
\hline $\mathrm{X}$ & $\mathrm{Y}$ & $\mathrm{SY}$ & $\mathrm{SZ}$ & $\mathrm{Result} /\left(\mathrm{Bq} \mathrm{m}^{-2}\right)$ \\
\hline 500 & 0 & 29 & 14 & $4.50 \times 10^{-3}$ \\
1000 & 0 & 50 & 23 & 13.59 \\
2000 & 0 & 100 & 37 & 55.00 \\
4000 & 0 & 190 & 54 & 118.32 \\
8000 & 0 & 340 & 78 & 70.00 \\
4500 & 50 & 205 & 60 & 115.10 \\
\multicolumn{4}{l}{$\mathrm{Q}=4 \times 10^{7} \mathrm{~Bq} \mathrm{sec}^{-1} \cdot \mathrm{u}=4 \mathrm{~m} \mathrm{sec}^{-1} \cdot \mathrm{h} 1=75$}
\end{tabular}

\section{CONCLUSION}

Using the diffusion equation, a mathematical model to calculate surface concentration of nuclear pollutants is constructed. Solving the equation by separation of variables and using some approximations leaded to a distribution represents a model for plume of radioactive pollutants dispersed in two directions normal to the wind direction in which the plume moves as an entire non-dispersible unit. Atmospheric eddy currents causes a turbulent diffusion, which makes the surface concentration results go far away from those of the pure mathematical description of the phenomenon as expressed by the diffusion equation. The result obtained here are very near to those achieved experimentally.

\section{REFERENCES}

1. Fredrick Warner and Roy Harrison, 1993. Radioecology after Chernobyl: Biogeochemical Pathways of Artificial Radionuclides. 1st Edn., John Wiley and Sons, Chichester, UK., ISBN: 0471-93168-3, pp: 367.

2. Farlow, S.J., 1982. Partial Differential Equations for Scientists and Engineers, 1st Edn., John Wiley and Sons, ISBN: 10: 048667620X, pp: 414.

3. Dass, T. and Sharma, S., 1998. Mathematical Methods in Classical and Quantum Physics. 1st Edn., University Press, Hayderabad, India, ISBN: 978-81-7371-089-6, pp: 716.

4. Arfken, G., 1985. Mathematical Methods for Physicists. 3rd Edn., Academic Press, Orlando, Florida, ISBN: 0120598205, pp: 985.

5. Bird, R.B., W.E. Stewart and E.N. Lightfoot, 2001. Transport Phenomena. 2nd Edn., John Wiley and Sons, New York, USA., ISBN: 0471410772, pp: 338 .

6. Cember, H., 1996. Introduction to Health Physics. 3rd Edn., McGraw-Hill, New York, USA., ISBN: 10: 0071054618 , pp: 731. 